auf Lukas 18,16. Auch hier liegt eine combination zweier bibelstellen vor: 'Perdam sapientiam sapientium et prudentiam prudentium reprobabo' $(1$. Korinther 1,19$)$ und 'Confiteor tibi, pater, domine coeli et terrae, quia abscondisti haec a sapientibus et prudentibus et revelasti ea parvulis' (Matthäus 11, 25; wörtlich ebenso Lukas 10,21).

$110 \mathrm{a}, 87$. Den plural blattern von blatt 'platte, schüssel', den die erste ausgabe hier hat, möchte ich doch nicht mit Zarncke (zu 38) als neutrale pluralbildung fassen, da das wort bei Brant stets femininum ist (vgl. 38. 56. 131. 164; Facetus 178. 436; thesmophagia 189. 201. 278. 587) und der plural blatten auch 44 vorkommt; es dürfte einfach ein druckfehler vorliegen.

JENA, 10. august 1915. ALBERT LEITZMANN.

\title{
GESCHMACK IN ANWENDUNG AUF DAS SCHÖNE.
}

Der abschnitt vom 'geschmack in anwendung auf das schöne' in Grimms Wörterbuch (sp. 3928) beschränkt sich im wesentlichen auf die wiedergabe dessen, was Rudolf Hildebrand in der Zs. für den deutschen unterricht (bd. 6,665 ff.) dargelegt hat. Als ergänzung zu den dort gegebenen belegen für die frühzeit des wortgebrauches dürften zwei weitere beispiele von interesse sein, die mich der zufall finden ließ.

In Nürnberg erschienen in den jahren 1694 und 1695 bei dem buchhändler Joh. Dan. Tauber zwei Molièreübersetzungen (vgl. M. Spirgatis, Die Nürnberger Molièreübersetzungen u.s.w. in: Sammlung bibliothekswissenschaftlicher arbeiten hrsg. von Karl Driatzko, heft 10, 79 ff.; ferner: P. Wohlfeil, Die deutschen Molièreübersetzungen, progr. Frankfurt a. M. 1904, dem ich den hinweis verdanke, und Bolte, Herrigs Archiv 82, $91 \mathrm{ff}$.). Jlie zweite iibersetzung (Histrio Gallicus etc. 1695), die an stelle der ersten, schlechten treten soll, betont, da $B$ sie möglichst getreu übersetzen will, und sieht sich daher vielfach gezwungen, hinter unverstïndlichen, dem französischen entlehnten wendungen die übliche ausdrucksweise in klammern beiznfügen. In der neunten scene von 'Jes précieuses ridicules' wo man von dem 'ol, oli' des dichters spricht, sagt Magdelon: 'Sans donte, et j'aimerois mieux avoir fail ce Oh, oh! qu'm poeme fepique'; und Mascarille 
antwortet: 'I'udieu! vous avez le goût bon'. Diesen letzten satz übersetzte die deutsche ausgabe von 1694: 'O GOtt/ihr seyd recht scharfisinnig'; die neue übersetzung von 1695 sagt: 'O Blut, sie hat einen guten geschmack'. Da indessen diese wendung den lesern noch unverständlich erscheinen mußte, so fügt die übersetzung in klammern hinzu: 'Sie urtheilt gar wohl'.

Auch ferner vermied man noch, wenn auch geschmack in übertragener bedeutung aus dem französischen.sprachgebrauch ïbernommen wurde, das deutsche wort (vgl. Grimm) und ließ das französische goît stehen. So auch in der letzten nummer der ersten deutschen moralischen wochenschrift 'Der Vernünfftler' in Hamburg (vgl. Karl Jacoby, Die ersten moralischen wochenschriften Hamburgs. Progr. Hamburg 1888). Hier sagt (am 30. mai 1714) der herausgeber Mattheson, daß er die zeitschrift aufgeben müsse, '.....maßen der gute Gout bey uns etwas spahrsam anzutreffen ...'

Erst als Gottsched und J. U. König dafür eintraten, fand das deutsche wort eingang.

\section{ILMENAU.}

\section{FRIEDRICH MICHAEL.}

\section{LITERATUR.}

(Verzeichnis bei der redaction eingegangener schriften.)

Kluge, Friedrich, Altdeutsches sprachgut im mittellatein. Proben eines Ducangius theodiscus (= Sitzungsberichte der Heidelberger akad. d. wiss., phil.-hist. klasse 1915, 12). Heidelberg, Winter 1915. - $16 \mathrm{~s}$.

Mieses, Josef, Die älteste gedruckte deutsche übersetzung des jüdischen gebetbuches a. d. jahre 1530 und ihr autor Anthonius Margaritha. Eine literarhistorische untersuchung. Wien, R. Löwit 1916. - 57 s. M. 2.00 . Mieses, Iatthias, Die entstehungsursache der jüdischen dialekte. Wien, R. Löwit 1915. - 120 s. M. 4.06.

Reidemeister, Gerhard, Die überlieferung des Seelentrostes. Teil I. (Diss.) Halle 1915. - $79 \mathrm{~s}$.

Rudolfs von Ems Weltchronik. Aus der Wernigeroder handschrift herausgegeben von Gustav Ehrismanu. Mit 3 tafeln in lichtdruck (=Deutsche texte des mittelalters hrsg. von der K. Preuß. Akademie d. wiss. Band XX). Berlin, Weidmann 1915. - XXXVII, 634 s,

Zupitza, Julius, Einführung in das studium des mittelhochdeutschen. Zum selbstunterricht für jeden gebildeten. 11. verb. aufl., besorgt von Franz Nobiling. Chemnitz und Leipzig, Wilh. Gronau 1914. - VIII, 130 s. 